Atmos. Chem. Phys., 17, 10109-10123, 2017

https://doi.org/10.5194/acp-17-10109-2017

(c) Author(s) 2017. This work is distributed under

the Creative Commons Attribution 3.0 License.

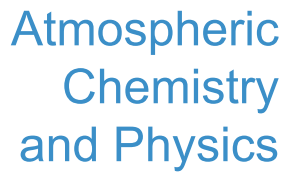

(c) (i)

\title{
Projected changes in haze pollution potential in China: an ensemble of regional climate model simulations
}

\author{
Zhenyu Han ${ }^{1}$, Botao Zhou ${ }^{1,2}$, Ying $\mathrm{Xu}^{1}$, Jia Wu${ }^{1}$, and Ying Shi ${ }^{1}$ \\ ${ }^{1}$ National Climate Center, China Meteorological Administration, Beijing, China \\ ${ }^{2}$ Collaborative Innovation Center on Forecast and Evaluation of Meteorological Disasters, Nanjing University of Information \\ Science \& Technology, Nanjing, China \\ Correspondence to: Botao Zhou (zhoubt@cma.gov.cn)
}

Received: 14 November 2016 - Discussion started: 6 February 2017

Revised: 27 July 2017 - Accepted: 27 July 2017 - Published: 29 August 2017

\begin{abstract}
Based on the dynamic downscaling by the regional climate model RegCM4 from three CMIP5 global models under the historical and the RCP4.5 simulations, this article evaluated the performance of the RegCM4 downscaling simulations on the air environment carrying capacity (AEC) and weak ventilation days (WVDs) in China, which are applied to measure haze pollution potential. Their changes during the middle and the end of the 21 st century were also projected. The evaluations show that the RegCM4 downscaling simulations can generally capture the observed features of the AEC and WVD distributions over the period 1986-2005. The projections indicate that the annual AEC tends to decrease and the annual WVDs tend to increase over almost the whole country except central China, concurrent with greater change by the late 21 st century than by the middle of the 21 st century. It suggests that annual haze pollution potential would be enlarged under the RCP4.5 scenario compared to the present. For seasonal change in the four main economic zones of China, it is projected consistently that there would be a higher probability of haze pollution risk over the Beijing-Tianjin-Hebei (BTH) region and the Yangtze River Delta (YRD) region in winter and over the Pearl River Delta (PRD) region in spring and summer in the context of the warming scenario. Over Northeast China (NEC), future climate change might reduce the AEC or increase the WVDs throughout the whole year, which favours the occurrence of haze pollution and thus the haze pollution risk would be aggravated. The relative contribution of different components related to the AEC change further indicates that changes in the boundary layer depth and the wind speed play leading roles in the AEC change over the BTH and NEC regions. In
\end{abstract}

addition to those two factors, the precipitation change also exerts important impacts on the AEC change over the YRD and PRD zones.

\section{Introduction}

Haze, as a phenomenon of severe air pollution, exerts remarkably adverse impacts on society and human health; thereby it is a high concern of the public and policy makers. Particularly in recent years, heavy haze events hit China frequently (Wang et al., 2014; Zhang et al., 2014) and caused serious damage in many aspects. For instance, they not only increased traffic accidents and delayed traffic (Wu et al., 2005, 2008) but also aggravated health problems including respiratory disease, heart disease, cancer, and premature death (Wang and Mauzerall, 2006; Xu et al., 2013). Thus, more and more attention has been paid to haze pollution in China.

The increasing trend of haze days in China during recent decades (Ding and Liu, 2014; Song et al., 2014) is documented to be largely attributed to human activities. Due to rapid economic development and urbanization, the pollutants emitted into the atmosphere have been increased, resulting in an intensification of haze pollution in China (Liu and Diamond, 2005; He et al., 2013; Y. S. Wang et al., 2013, 2016). Climate change also plays an important role (Jacob and Winner, 2009; Wang et al., 2016; Cai et al., 2017). Some studies have indicated that the reduction of surface wind speed, surface relative humidity, and precipitation in recent decades (Gao, 2008; Guo et al., 2011; Jiang et al., 2013; Song et al., 2014; Ding and Liu, 2014; Yang et al., 2016) provide un- 
favourable conditions for the sedimentation and diffusion of air pollutants, and thus increase the occurrence of haze pollution in China. Besides, the Arctic sea ice declining under global warming contributes positively to the increase in haze days in eastern China (Wang et al., 2015; Wang and Chen, 2016; Zou et al., 2017). Other influential climate factors for the increase in haze pollution in China, such as the weakening of the eastern Asian winter monsoon (Li et al., 2015; Yin et al., 2015) and the northward shifting of the eastern Asian jet (Chen and Wang, 2015), are also highlighted. In summary, the combined effects of increased pollutants and climate change are responsible for the haze pollution in China.

IPCC AR5 reported that continued emissions of greenhouse gases will cause further changes in all components of the climate system (IPCC, 2013). From the point of view of the CMIP5 projected change in climate conditions, there are both positive and negative contributors to the haze pollution in China. For example, the projected increase in precipitation (Xu and Xu, 2012; Tian et al., 2015; Wu et al., 2015b) is expected to reduce haze pollution, whereas the decrease of the Arctic sea ice extent (IPCC, 2013) and the weakening of the eastern Asian winter monsoon (H. J. Wang et al., 2013) are inclined to increase haze pollution. So, how haze pollution in China will change under the future warming scenario is still an open issue.

Air environment carrying capacity (AEC), which is a combined metric used to measure atmospheric capacity in transporting and diluting pollutants into the atmosphere, provides a direct way to investigate the change in the haze pollution potential. When the AEC is low (high), it is unfavourable (favourable) for the diffusion and cleaning of the pollutants, and thus haze pollution is (not) prone to occur. So far, the AEC has been applied in the operation of the China Meteorological Administration (CMA) to forecast haze pollution potential (Kang et al., 2016). On the other hand, CMIP5 global climate models (GCMs) show some limitations in simulating regional climate due to their relatively coarse resolutions (Giorgi et al., 2009). Regional climate models (RCMs) with higher resolutions are demonstrated to outperform global models on the regional scale (Lee and Hong 2014; Wu et al., 2015a; Gao et al., 2012, 2017). Thus, this study aims to project changes in the haze pollution potential in China from the AEC perspective, based on the downscaling simulations of the regional climate model RegCM4 under the RCP4.5 scenario.

\section{Model, data, and method}

\subsection{Data, regional climate model, and simulations}

The regional climate model RegCM4 used in this study is developed by the ICTP (Giorgi et al., 2012) and applied widely around the world. The model has the horizontal resolution of $25 \mathrm{~km}$ and 18 vertical sigma layers with the top at
$50 \mathrm{hPa}$. Based on the study of Gao et al. (2016, 2017), we selected a suite of physical parameterization schemes suitable for the simulation of the Chinese climate, including the Emanuel convection scheme (Emanuel, 1991), the radiation package of the CCM3 model for atmospheric radiative transfer (Kiehl et al., 1998), the non-local formulation of Holtslag (Holtslag et al., 1990) for the planetary boundary layer, the SUBEX parameterization for large-scale precipitation (Pal et al., 2000), and the CLM3.5 for land surface process (Oleson et al., 2008). The land cover data were updated based on the vegetation atlas of China (Han et al., 2015).

The domain for the downscaling simulations is the region recommended by CORDEX-East Asia phase II (Giorgi et al., 2009), covering China and adjacent regions. The RegCM 4 simulations, called EC, HAD, and MPI, were driven at $6 \mathrm{~h}$ intervals by the historical (1979-2005) and RCP4.5 (20062099) simulations from three CMIP5 global models, i.e. ECEARTH, HadGEM2-ES, and MPI-ESM-MR, respectively. In CMIP5, $\sim 20$ GCMs provide the $6 \mathrm{~h}$ outputs of wind speed, temperature, and humidity for dynamical downscaling. However, to drive RCM modelling, the ratio of the resolution between GCMs and RCMs should not exceed 6-8. So, only those GCMs with a resolution of $1-2^{\circ}$ or higher can be used to drive RegCM4 simulations. Due to the availability of CMIP5 GCMs and considering large volume of outputs for $\sim 120$-year RegCM4 simulations, we just used these three GCMs for this study. The average of the three simulations with equal weight is taken as the ensemble mean. The historical simulation denotes the past climate, and the RCP4.5 represents the medium-low radiative forcing scenario with the radiative forcing peaking at $4.5 \mathrm{~W} \mathrm{~m}^{-2}$ by 2100 (Taylor et al., 2012). Readers can visit http://cmip-pcmdi.llnl.gov/cmip5 for information about the three CMIP5 models and the forcing.

To validate the performance of the RegCM4 downscaling simulations, the ERA-Interim reanalysis data set (Uppala et al., 2008) with the horizontal resolution of $0.75^{\circ} \times 0.75^{\circ}$ was employed as observations, including $6 \mathrm{~h}$ boundary layer height, precipitation, geopotential height, and wind speed.

\subsection{Analysis method}

The AEC considers the processes of wet deposition and ventilation and is expressed in the form:

$\mathrm{AEC}=C_{\mathrm{S}} \cdot\left(W_{\mathrm{r}} \cdot R \cdot \sqrt{S}+\frac{\sqrt{\pi}}{2} \cdot U_{\mathrm{BL}} \cdot H\right)$,

where $C_{\mathrm{s}}$ is the standard concentration of air pollutant (here, the value is $75 \mu \mathrm{g} \mathrm{m}^{-3}$, standard concentration for $\mathrm{PM}_{2.5}$ in China), $W_{\mathrm{r}}$ is washout constant $\left(6 \times 10^{5}\right), R$ is precipitation, $S$ is unit area and defined as $2500 \mathrm{~km}^{2}, U_{\mathrm{BL}}$ is mean wind speed averaged within the boundary layer, $H$ is boundary layer height (Xu and Zhu, 1989). High (low) AEC is disadvantageous (advantageous) for the occurrence of haze pollution, indicating low (high) haze pollution potential. It should 
be pointed out that the AEC measures atmospheric carrying capacity in transporting and diluting pollutants. It does not reflect real emission characteristics. The $C_{\mathrm{s}}$ is the standard concentration of air pollutant, not the real concentration of the pollutant emitted into the air. For different pollutants, different values can be fixed for $C_{\mathrm{s}}$. Because what we are concerned with in this study is the haze pollution potential, its value is set as the standard concentration for $\mathrm{PM}_{2.5}$ in China.

The term $U_{\mathrm{BL}} \cdot H$ is the ventilation coefficient (Krishnan and Kunhikrishnan, 2004). A large ventilation coefficient means that a deeper boundary layer can dilute pollutants and strong winds can remove local pollutants, unfavourable for haze occurrence, and vice versa. If each of the $6 \mathrm{~h}$ ventilation coefficients within 1 day is less than $6000 \mathrm{~m}^{2} \mathrm{~s}^{-1}$, this day is counted as one weak ventilation day (WVD) (Leung and Gustafson, 2005). Longer WVDs indicate more haze pollution incidents. The threshold of $6000 \mathrm{~m}^{2} \mathrm{~s}^{-1}$ for the ventilation coefficient was widely used, not only in the USA (Hanson and McKee, 1983; Leung and Gustafson, 2005; Trail et al., 2013) but also in other places such as India (Goyal and Rao, 2007; Manju et al., 2002), Athens (Kassomenos et al., 1995) and Thailand (Pimonsree, 2008). A sensitivity analysis shows that there is little change in the relationship between WVDs and the haze days if using different thresholds to calculate WVDs.

According to Eq. (1), the AEC change results from changes in precipitation, wind speed, and boundary layer depth, which can be simplified as

$\Delta \mathrm{AEC}=\alpha \cdot \Delta R+\beta \cdot \Delta\left(U_{\mathrm{BL}} \cdot H\right)$,

where $\alpha=C_{\mathrm{s}} \cdot W_{\mathrm{r}} \cdot R, \beta=C_{\mathrm{s}} \cdot \frac{\sqrt{\pi}}{2}$, and $\Delta$ represents the difference between the future and present-day climate (RCP4.5 minus reference period).

The Eq. (2) could be further decomposed as follows:

$$
\begin{aligned}
& \Delta \mathrm{AEC}=\alpha \cdot \Delta R+\beta \cdot \Delta U_{\mathrm{BL}} \cdot H_{\mathrm{pd}}+\beta \cdot\left(U_{\mathrm{BL}}\right)_{\mathrm{pd}} \cdot \Delta H \\
& +\beta \cdot \Delta U_{\mathrm{BL}} \cdot \Delta H+\mathrm{TR} .
\end{aligned}
$$

The subscript "pd" denotes the present-day climate. The first to third terms in the right-hand side are associated with changes in precipitation, wind speed within the boundary layer, and boundary layer depth. The fourth term is a nonlinear term including the contribution of changes in both wind speed and boundary layer depth. Since we use $6 \mathrm{~h}$ data for the AEC calculation but monthly mean data for the diagnosis of the change, the last term TR (transient term, deviation from monthly mean) cannot be ignored and is obtained as a residual.

The pattern-amplitude projection (PAP) method (Park et al., 2012) is applied to quantify the relative contributions of individual processes $P_{\mathrm{i}}$ to the AEC change over certain regions.

$\mathrm{P}_{\mathrm{i}}=\frac{\left\langle\Delta \mathrm{AEC}_{\mathrm{i}} \cdot \Delta \mathrm{AEC}\right\rangle}{\langle\Delta \mathrm{AEC} \cdot \Delta \mathrm{AEC}\rangle}$, in which \langle\rangle represents area mean, $\triangle \mathrm{AEC}_{\mathrm{i}}$ represents components in the right-hand side of Eq. (3).

As stated above, a low (high) AEC is favourable (unfavourable) for the occurrence of haze pollution. Longer (shorter) WVDs correspond to more (less) haze pollution incidents. To verify this conclusion, we calculated the quantized relationship between the haze days and the AEC and WVDs during the period 1980-2016 in the observation. The data of the haze days, which are based on daily visibility and relative humidity records from $\sim 2400$ observation stations in China, are available from the CMA. The correlation analysis shows significantly negative correlations between the haze days and the AEC and significantly positive correlations between the haze days and WVDs over eastern China where the haze mainly occurs.

\section{Performance of the downscaling simulations}

The performance of the RegCM4 downscaling simulations on the AEC spatial pattern is firstly evaluated through the comparison with the observation. As shown in Fig. 1a, the observed AEC is in general large in western China, with the maxima located over Tibet. Low AEC is found mainly over central and eastern China, north-western Xinjiang, and parts of Northeast China. The simulated AEC distributions from the ensemble (Fig. 1b) and its members (Fig. 1c-e) show a general resemblance to the observation. The spatial correlation coefficients between the simulation and the observation are all higher than 0.75 (Table 1). On the national average, the root mean square error (RMSE) is small for the ensemble mean and each member, which varies between 0.47 and 0.53 (Table 1). Nevertheless, there are also some deficits in the simulations. For example, the AEC is underestimated over southern Xinjiang and overestimated over parts of northern China. Our analysis indicates that the simulation bias in boundary layer depth is the major factor for the simulated AEC bias over most parts of China (figure not shown).

We further present the observed and simulated distribution of the seasonal AEC in China during 1986-2005. For the observation, the winter AEC is the lowest among the four seasons in a broad region of China (Fig. 2a). In spring, the AEC increases significantly and the regions with high AEC expand. Central eastern China is dominated by low capacity (Fig. 2c). Compared with the case in spring, the summer AEC increases over central China but decreases slightly over Tibet and Northeast China (Fig. 2e). The AEC distribution in autumn is similar to that in winter but with a larger capacity over the regions except Tibet (Fig. 2g). The seasonal variation of the AEC in the ensemble simulation agrees with that in the observation, although there are some discrepancies (Fig. 2b, d, f, and h). The spatial correlation coefficient between the simulation and the observation ranges from 0.60 to 0.79 and the RMSE is in the range of 0.47 to 0.75 for the national average in four seasons (Table 2). 

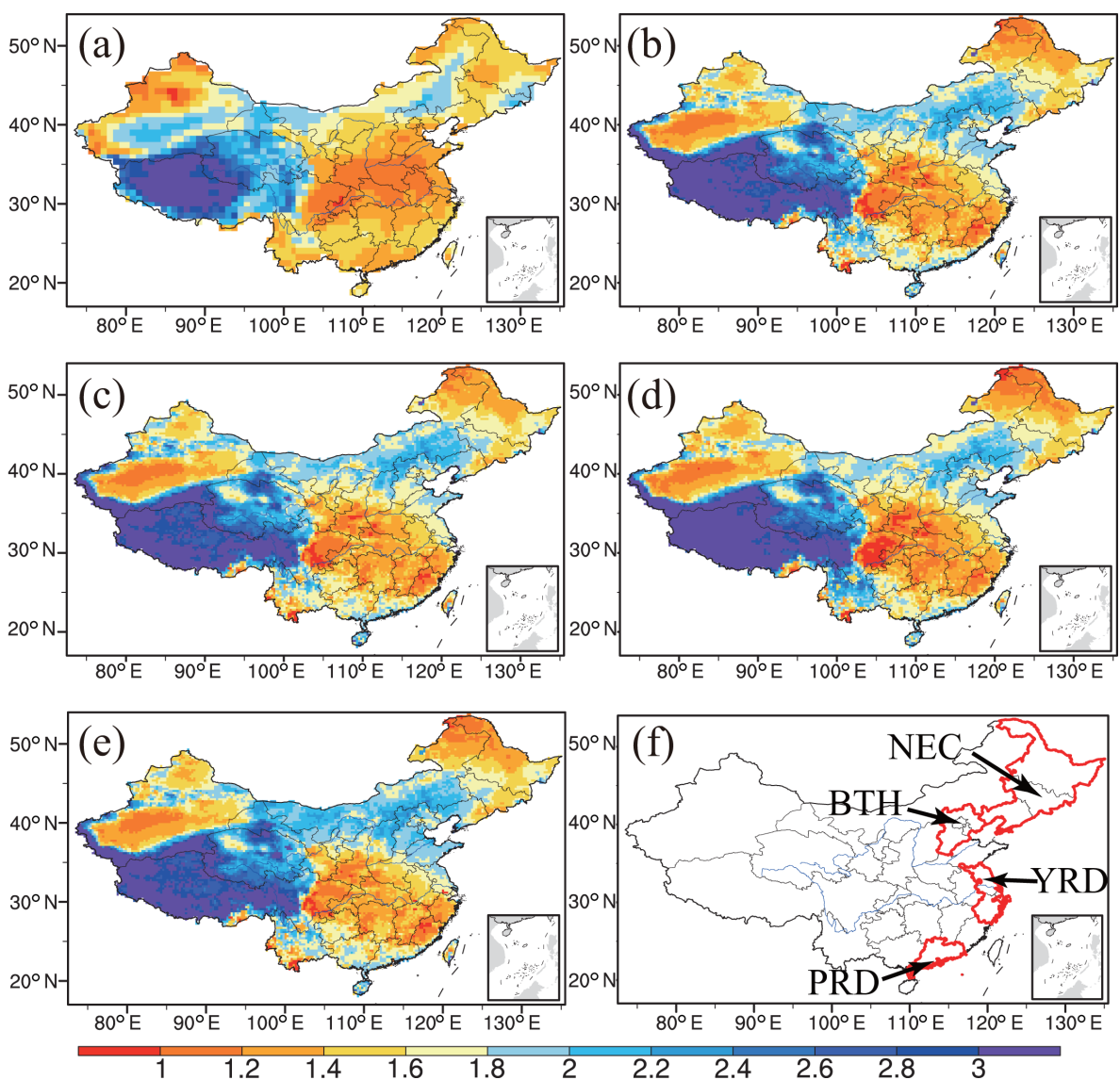

Figure 1. Spatial distribution of annual AEC (unit: $10^{4} \mathrm{ta}^{-1} \mathrm{~km}^{-1}$ ) during 1986-2005: (a) observation, (b) ensemble, (c) EC, (d) HAD, (e) MPI. (f) Four main economic zones of China, Beijing-Tianjin-Hebei region (BTH), Northeast China (NEC), Yangtze River Delta economic zone (YRD), and Pearl River Delta economic zone (PRD).

Table 1. Statistic results for the simulation skills in annual mean AEC for the period of 1986-2005.

\begin{tabular}{lrr}
\hline Simulations & $\begin{array}{r}\text { Pattern correlation } \\
\text { coefficient (CC) }\end{array}$ & $\begin{array}{r}\text { Root mean square } \\
\text { error (RMSE) }\end{array}$ \\
\hline EC & 0.76 & 0.47 \\
HAD & 0.79 & 0.53 \\
MPI & 0.76 & 0.47 \\
Ensemble & 0.77 & 0.48 \\
\hline
\end{tabular}

The WVD distribution during 1986-2005 in the observation and the ensemble simulation is displayed in Fig. 3a and $\mathrm{b}$, respectively. It is noticed that the simulated pattern and the observed pattern are approximate to each other. Namely, the number of weak ventilation days per year is relatively small over Tibet but relatively large over central and eastern China, Northeast China, the south of northern China and Xinjiang. The spatial correlation between them is 0.75 . However, we also note that the WVD is overestimated by the ensemble simulation.
The wet deposition is observed to be large over southern China and the southern edge of the Tibetan Plateau but small over north-western China (Fig. 3c). According to Eq. (1), the wet deposition pattern exactly corresponds to the distribution of precipitation. The observed features can also be captured by the ensemble simulation (Fig. 3d). The spatial correlation coefficient between the simulation and the observation is up to 0.85 .

In brief, the downscaling simulations of the RegCM4 can reasonably reproduce the observed characteristics of the distribution of the AEC, WVC, and wet deposition in China. This provides justification to use them for the future projection.

\section{Projected changes}

Figure 4 exhibits the ensemble projected changes in AEC, WVC and wet deposition during the middle of the 21 st century (2046-2065) and the end of the 21st century (20802099) relative to the reference period 1986-2005. The periods 2046-2065 and 2080-2099 are commonly used to rep- 

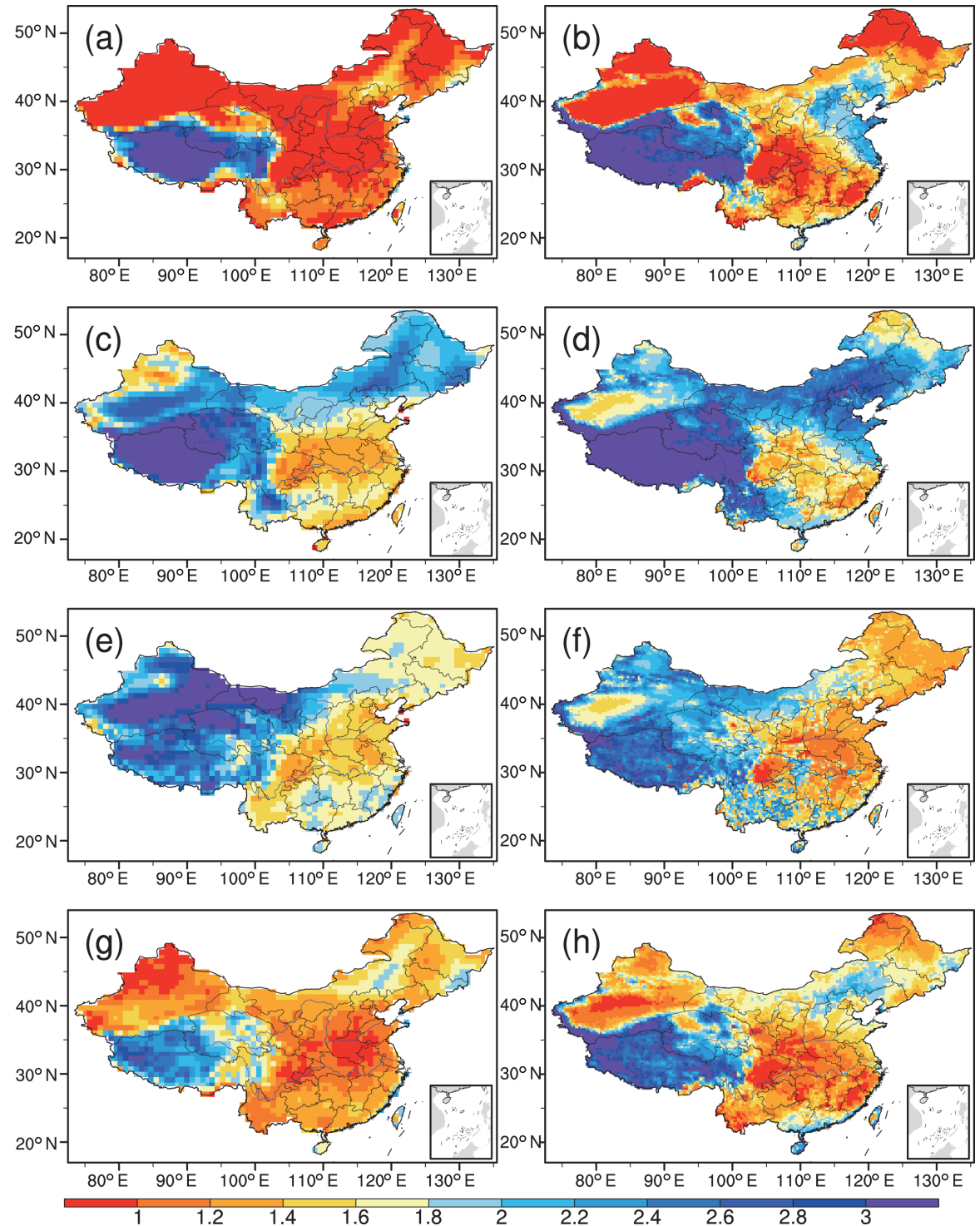

Figure 2. Spatial distribution of seasonal AEC (unit: $10^{4} \mathrm{ta}^{-1} \mathrm{~km}^{-1}$ ) during 1986-2005: (a-b) winter, (c-d) spring, (e-f) summer, (g-h) autumn. Left panel is for the observation and the right panel is for the ensemble simulation.

Table 2. Statistic results for the ensemble simulation skills in seasonal AEC for the period of 1986-2005.

\begin{tabular}{lrr}
\hline Season & $\begin{array}{r}\text { Pattern correlation } \\
\text { coefficient (CC) }\end{array}$ & $\begin{array}{r}\text { Root mean square } \\
\text { error (RMSE) }\end{array}$ \\
\hline Winter & 0.79 & 0.75 \\
Spring & 0.75 & 0.67 \\
Summer & 0.60 & 0.57 \\
Autumn & 0.78 & 0.47 \\
\hline
\end{tabular}

resent near term and long term in the CMIP5 projection, respectively (IPCC, 2013). A general decrease in AEC and an overall increase in WVC are projected over almost the whole country except central China in the context of the RCP4.5 scenario. The change in magnitude is larger by the end of the 21 st century than by the middle of the 21 st century. The maximum decrease in AEC appears at the edge of the QinghaiTibet Plateau and the Loess Plateau, with the percentage change being $4 \%$ for the middle of the 21 st century and $5 \%$ for the end of the 21 st century. The relatively large decreases are located in south-western China, north of northern China, Northeast China, and Inner Mongolia (Fig. 4a and b). The increase in WVDs is projected to be particularly pronounced in western and northern China (Fig. 4c and d). The three ensemble samples agree well on the sign of the changes, indicative of a good consistency in the projection. In contrast, there would be an increasing tendency for the AEC and a de- 

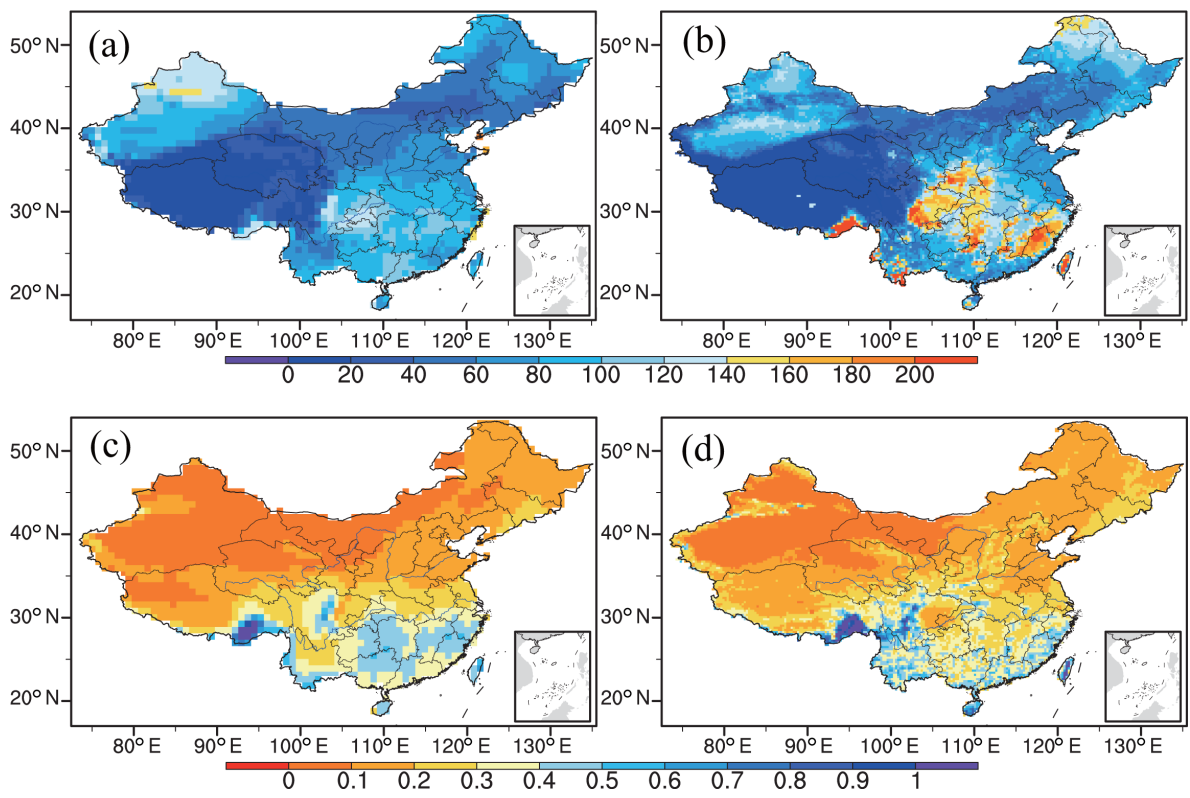

Figure 3. Spatial distribution of (a-b) the number of weak ventilation days per year and (c-d) wet deposition (unit: $\left.10^{4} \mathrm{ta}^{-1} \mathrm{~km}^{-1}\right)$ during 1986-2005: (a, c) observation, (b, d) ensemble simulation.
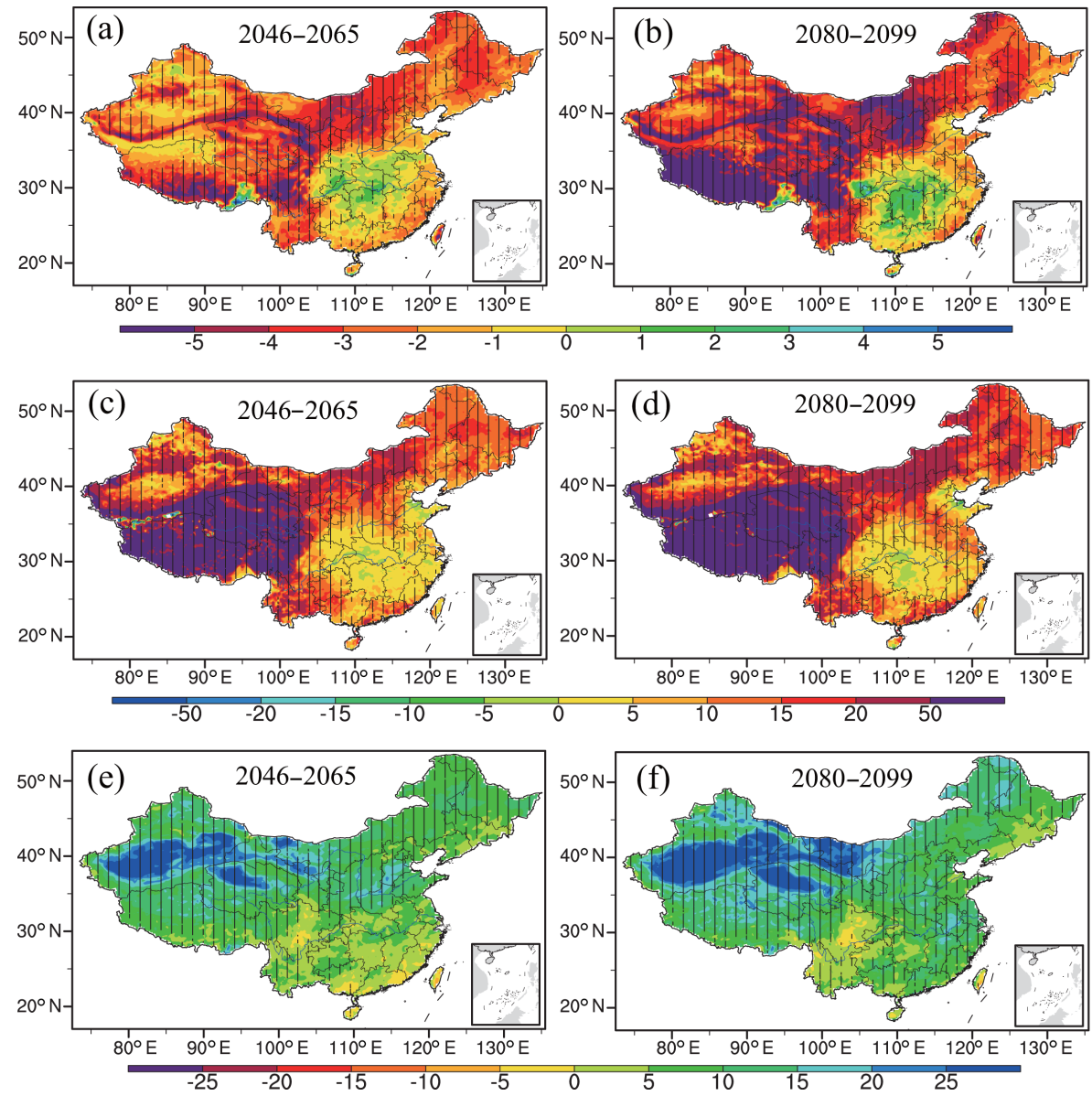

Figure 4. Ensemble projected percentage changes (relative to 1986-2005) in (a-b) AEC, (c-d) WVDs, and (e-f) wet deposition during (a, c, e) 2046-2065 and (b, d, f) 2080-2099. Hatched regions indicate all ensemble members agree on the sign of change. 

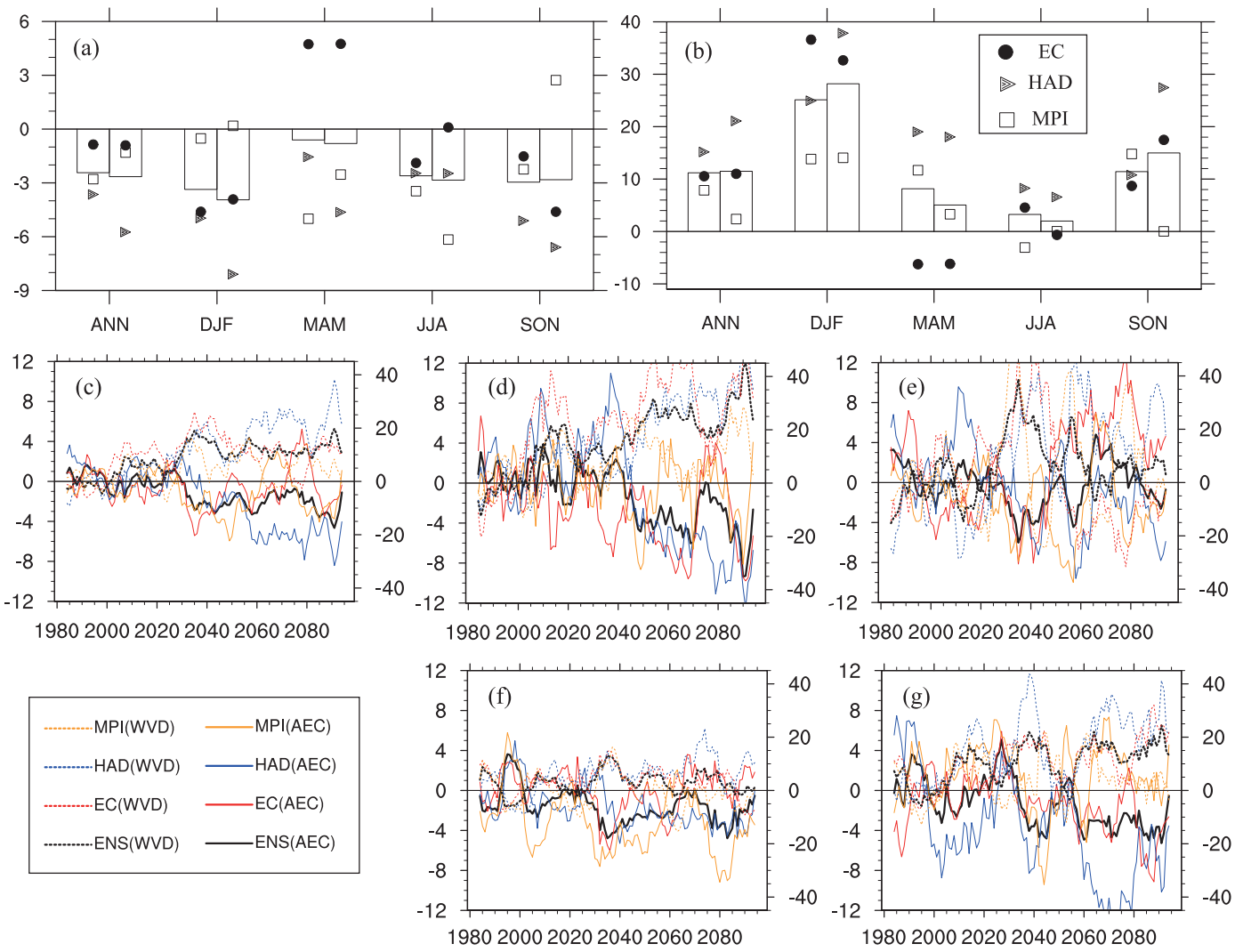

Figure 5. Range of projected percentage changes (relative to 1986-2005) in (a) AEC and (b) WVDs during 2046-2065 and 2080-2099, and 9a running mean time series of percentage changes in (c) annual, (d) winter (DJF), (e) spring (MAM), (f) summer (JJA), (g) autumn (SON) for the Beijing-Tianjin-Hebei region. In panels (a)-(b), the bars represent the ensemble projection and the marks represent the individual projection of the three members; the left (right) bar in each group is for 2046-2065 (2080-2099). In panels (c)-(g), the solid (dashed) lines represent changes in AEC (WVDs).

creasing tendency for WVDs over central China where the climatological capacity is low in the reference period 19862005. However, the sign of the projected change is inconsistent among the three ensemble samples. Compared with the ensemble projection, the EC and HAD show a relatively large discrepancy for the sign of the projected change in AEC and WVDs, respectively (figures not shown).

For the change in wet deposition, a general increase is projected across China, also with greater change in 2080-2099 than in 2046-2065 (Fig. 4e and f). In addition, we can find inconsistent signs of the projected change over southern China during 2046-2065 (Fig. 4e) and over some parts of northeastern China during 2080-2099 (Fig. 4f). The inconsistency during 2046-2065 (2080-2099) is mainly due to the difference between the HAD (MPI) projection and the other two ensemble members (figures not shown).

Following, we turn to examine the seasonal and annual changes in the AEC and WVDs over the four main economic zones of China (Fig. 1f) which suffer severely from the haze pollution at present, i.e. Beijing-Tianjin-Hebei region (BTH), Northeast China (NEC), Yangtze River Delta economic zone (YRD), and Pearl River Delta economic zone (PRD) in more detail.

\subsection{Beijing-Tianjin-Hebei region}

As shown in Fig. 5a, the ensemble projection indicates a decrease of the AEC in all four seasons during the middle of the 21 st century. The percentage change relative to $1986-2005$ is the lowest in spring and the largest in winter. The changes in summer and autumn are between -2 and $-3 \%$. The three ensemble members agree on the sign of the changes in all seasons except spring but with a different spread. For the summer season, the spread is the smallest. While in other seasons, it is close to or larger than the ensemble projected change. During the end of the 21st century, the decrease of the AEC is further enhanced, with the largest enhancement occurring in winter. Moreover, the spread in general becomes much larger. For annual change, both the ensemble and its members project that the AEC would reduce during the middle and the end of the 21st century with the larger amplitude in the latter period. 

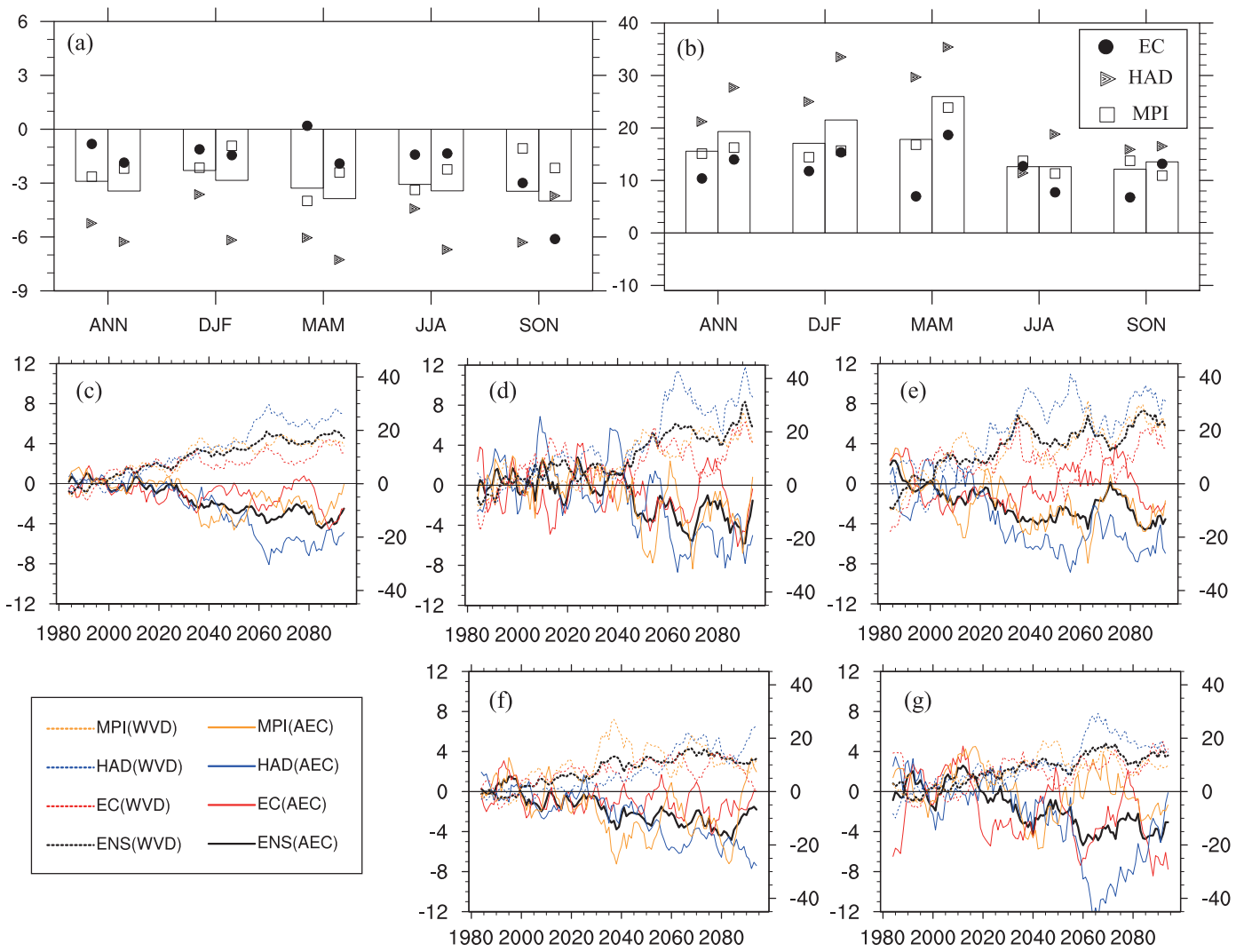

Figure 6. Same as Fig. 5 but for Northeast China.

As for WVDs (Fig. 5b), an increasing tendency is projected by the ensemble for annual and seasonal mean during the middle of the 21 st century. The change is the smallest in summer and the largest in winter. The ensemble members show good agreement with the positive change in winter, autumn, and the annual mean. During the late 21 st century, the increase in WVDs is further enlarged in winter and autumn while it is reduced in spring and summer. There is no appreciable change for the annual mean compared to that in the middle of the 21 st century. Only for the winter season and annual mean, all the individual simulations consistently show the same projection as the ensemble.

\subsection{Northeast China}

The annual and seasonal AEC are projected by the ensemble to decrease during the middle of the 21st century, and the percentage changes are comparable among the four seasons and annual mean (Fig. 6a). The ensemble members also consistently project a negative tendency except in spring. Compared with the middle of the 21 st century, the case for the end of the 21st century is similar but with larger decrease. Besides, all the three ensemble members show good consistency for the projection.

WVDs are projected by the ensemble and its members to increase during the middle and the end of the 21 st century for the annual mean and all four seasons (Fig. 6b). Similarly, the projected change is larger during the end of the 21st century than during the middle of the 21 st century, with the largest increase appearing in spring.

\subsection{Yangtze River Delta economic zone}

The ensemble projection indicates that the AEC would decrease for the annual mean and all the seasons except autumn (Fig. 7a). The percentage change is the smallest in spring (with the decrease of less than 1\%) and the greatest in winter (with the decrease of more than $3 \%$ ). The counterparts for summer and autumn are about -2 and $1 \%$, respectively. However, large spread exists among the projections of the three ensemble members. Only for winter and the annual mean, they project the same sign of the change. At the end of the 21st century in the ensemble projection, the decrease in AEC is enhanced to $6 \%$ in winter. Consistent change is projected by the ensemble members. In contrast, the decrease in summer and the increase in autumn are weakened compared to the middle of the 21st century. A slight increase in the $\mathrm{AEC}$ is found in spring. For annual mean AEC, the decrease is somewhat larger by the end of the 21 st century than by the middle of the 21 st century.

WVDs for the annual mean, winter and spring are projected by the ensemble to increase, with a larger change dur- 

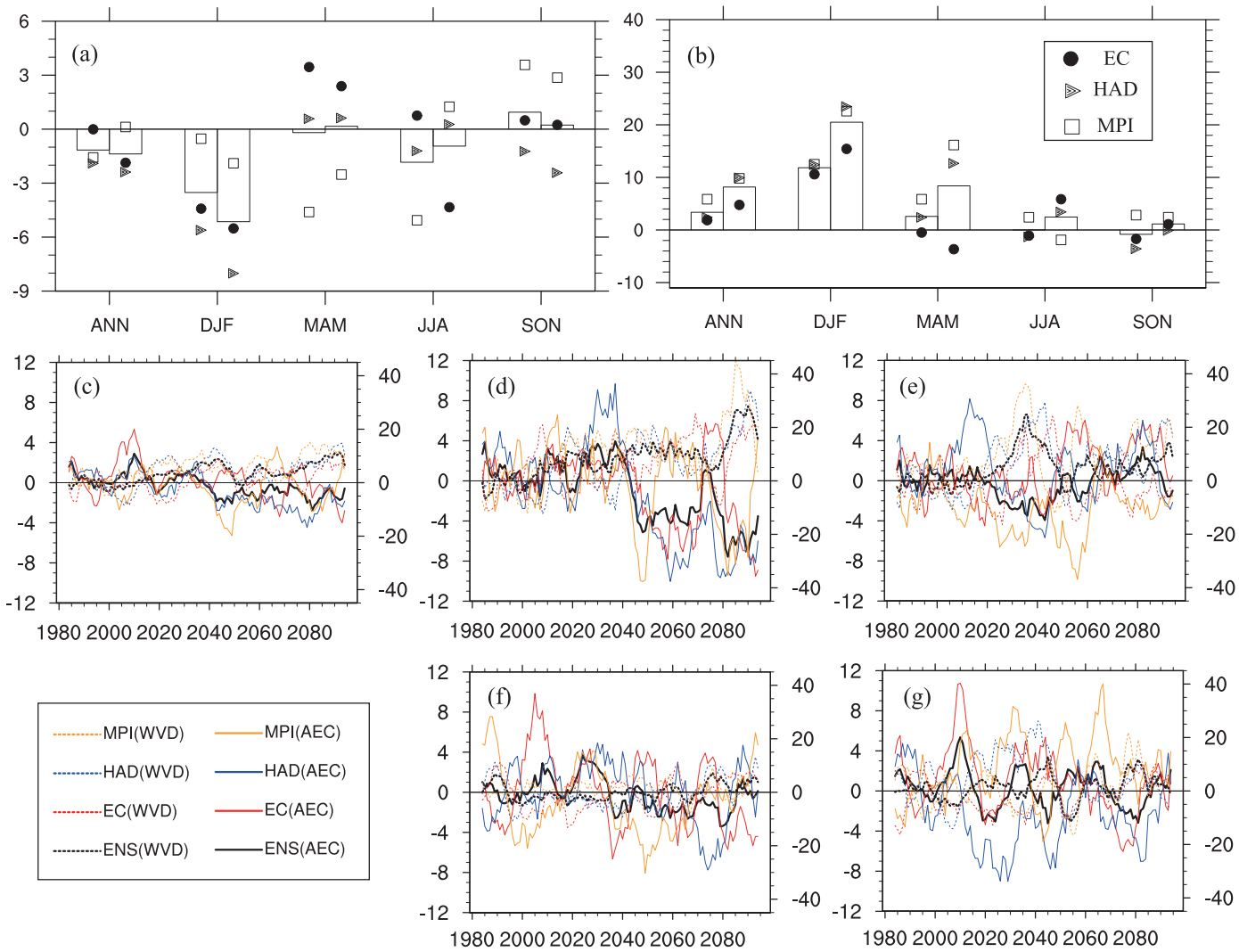

Figure 7. Same as Fig. 5 but for the Yangtze River Delta economic zone.

ing the end of the 21st century than during the middle of the 21 st century (Fig. 7b). The greatest change occurs in winter. For summer, the ensemble projects that WVDs almost remains unchanged during the middle of the 21 st century but increases at the end of the 21 st century. For autumn, the ensemble projects that WVDs decrease slightly during the middle of the 21 st century but increase slightly by the end of the 21 st century. The ensemble members show good consistency of the projections for winter and the annual mean during both periods.

\subsection{Pearl River Delta economic zone}

As projected by the ensemble (Fig. 8a), the annual, spring and summer AECs would decrease. Such a decrease is relatively larger during the middle of the 21 st century than during the end of the 21 st century and the greatest decrease occurs in spring. For winter, the AEC is projected to increase and be comparable during the middle and the end of the 21st century. For autumn, the projected AEC decreases by about $1 \%$ over the period 2046-2065 and increases by about $0.5 \%$ over the period 2080-2099. However, the projections from the three members are not consistent for all four seasons.

The ensemble projects an increase in WVDs for the annual mean and four seasons, with the greatest increase in summer during the middle of the 21st century (Fig. 8b). The indi- vidual members consistently show the positive change for spring, summer, and the annual mean. Compared with the middle of the 21st century, the increase in WVDs is reduced in summer but enhanced for the annual mean and the remaining seasons during the late 21 st century. The autumn is the season with the maximum change. The individual members still show the same projections as the ensemble for the sign of change for spring, summer, and the annual mean.

The consistency of the three ensemble members on the direction of the projected change, which can be used to visualize the uncertainty in the projection, is further summarized in Table 3. In general, although there are some uncertainties on the regional changes, the three members consistently project a decrease of the AEC or an increase in WVDs for the annual mean over the four economic zones, especially over the Beijing-Tianjin-Hebei region and Northeast China. It signifies that future climate change will contribute positively to the haze pollution in these regions. For seasonal change, a decrease in AEC or increase in WVDs is consistently projected to appear in all four seasons over Northeast China. It suggests that there would be an increase in haze pollution potential throughout the whole year. Besides, the consistent projections indicate a higher potential risk of haze pollution over the Beijing-Tianjin-Hebei region and the Yangtze River 

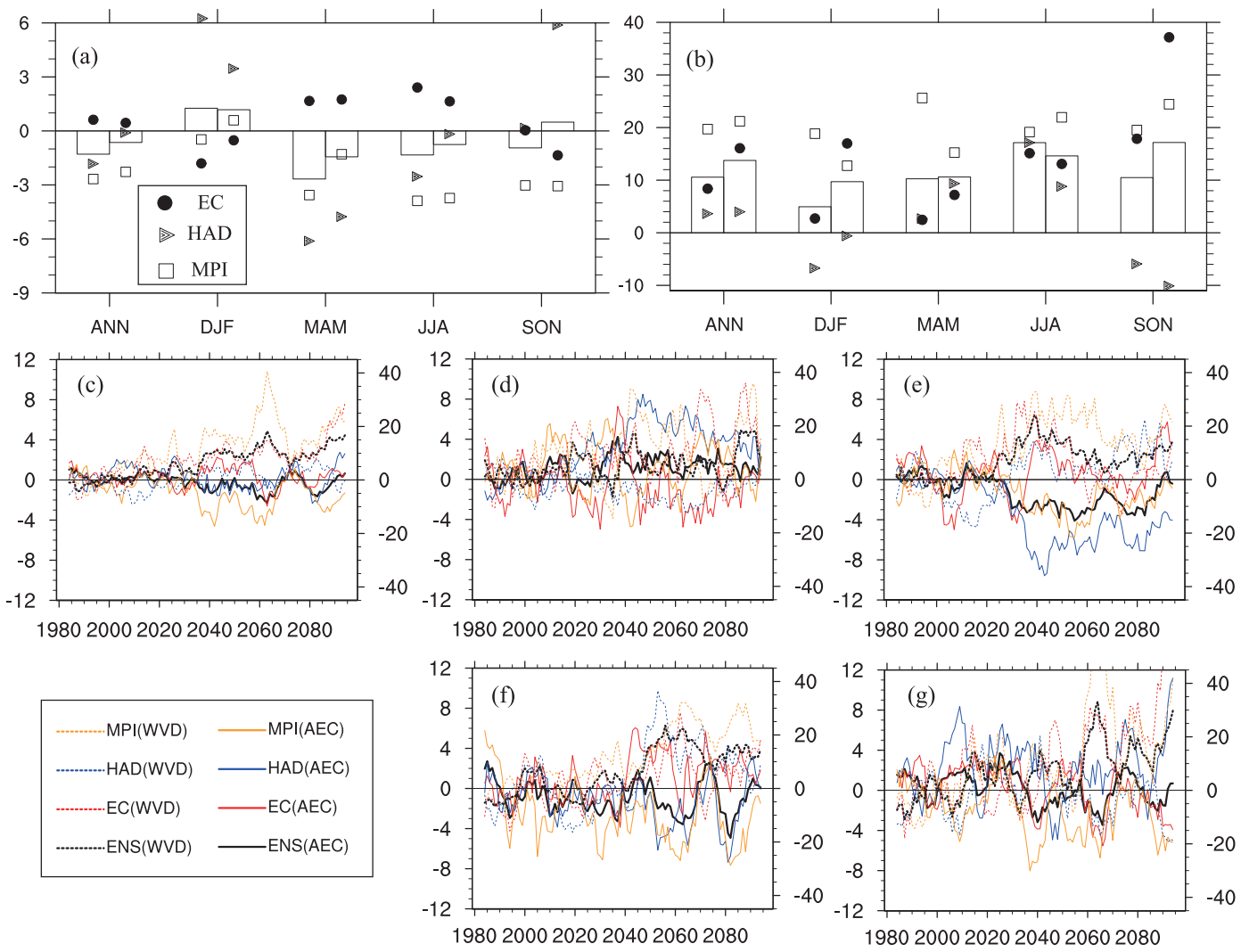

Figure 8. Same as Fig. 5 but for the Pearl River Delta economic zone.

Table 3. The consistency of the three ensemble members on the direction of the projected change over the four economic zones of China. Consistent projection of the decrease in AEC is marked by $\sqrt{ }$ and that on the increase in WVDs is marked by $*$.

\begin{tabular}{|c|c|c|c|c|c|c|}
\hline Economic zone & Period & ANN & DJF & MAM & JJA & SON \\
\hline \multirow[t]{2}{*}{ BTH } & 2046-2065 & $\sqrt{ }^{*}$ & $\sqrt{ }^{*}$ & & $\sqrt{ }$ & $\sqrt{ }^{*}$ \\
\hline & 2080-2099 & $\sqrt{ }^{*}$ & * & & & \\
\hline \multirow[t]{2}{*}{ NEC } & $2046-2065$ & $\sqrt{ }^{*}$ & $\sqrt{ }^{*}$ & * & $\sqrt{ }^{*}$ & $\sqrt{ } *$ \\
\hline & 2080-2099 & $\sqrt{ }^{*}$ & $\sqrt{ }^{*}$ & $\sqrt{ }^{*}$ & $\sqrt{ } *$ & $\sqrt{ } *$ \\
\hline \multirow[t]{2}{*}{ YRD } & 2046-2065 & $\sqrt{ }^{*}$ & $\sqrt{ }^{*}$ & & & \\
\hline & 2080-2099 & * & $\sqrt{ }^{*}$ & & & \\
\hline \multirow[t]{2}{*}{ PRD } & 2046-2065 & * & & * & * & \\
\hline & $2080-2099$ & * & & $*$ & $*$ & \\
\hline
\end{tabular}

Delta region in winter and over the Pearl River Delta zone in spring and summer.

The temporal evolution of the annual and seasonal AEC and WVDs over the four main economic zones are also plotted (Figs. $5-8 \mathrm{c}-\mathrm{g}$ ), and the corresponding trend values projected by the ensemble for the period of 2016-2099 are summarized in Table 4. Theil-Sen trend analysis (Theil, 1950; Sen, 1968) was used to estimate the trends and the nonparametric Mann-Kendall test (Mann, 1945; Kendall, 1975) was used for significant test. Generally, the secular variations of the AEC and WVDs show some diversity across different seasons over the regions except NEC where a decrease in AEC and an increase in VWD is projected uniformly. Nevertheless, for the trends significant above the $95 \%$ level, it is interesting to notice that the decrease in AEC is mostly accompanied by an increase in WVDs, for instance for winter over TBH, for the annual mean and all the seasons over NEC, for the annual mean, winter and summer over YRD, and for the annual mean and autumn over PRD. 
Table 4. Trends of AEC and WVDs (\%/10a) over the four economic zones of China, based on a 9-year running mean time series of the percentage change during 2016-2099. Asterisks indicate the trends are statistically significant above the $95 \%$ confidence level.

\begin{tabular}{llrrrrr}
\hline Economic zone & Variable & ANN & DJF & MAM & JJA & SON \\
\hline BTH & AEC & $-0.41^{*}$ & $-0.96^{*}$ & 0.02 & $-0.19^{*}$ & $-0.80^{*}$ \\
& WVDs & 0.33 & $2.30^{*}$ & $-1.53^{*}$ & $-0.51^{*}$ & 0.55 \\
\hline NEC & AEC & $-0.46^{*}$ & $-0.76^{*}$ & $-0.26^{*}$ & $-0.41^{*}$ & $-0.61^{*}$ \\
& WVDs & $1.49^{*}$ & $2.60^{*}$ & $1.30^{*}$ & $0.73^{*}$ & $0.97^{*}$ \\
\hline YRD & AEC & $-0.27^{*}$ & $-1.17^{*}$ & $0.32^{*}$ & $-0.45^{*}$ & -0.02 \\
& WVDs & $0.51^{*}$ & $0.88^{*}$ & -0.26 & $0.71^{*}$ & -0.15 \\
\hline PRD & AEC & $-0.14^{*}$ & -0.03 & $-0.22^{*}$ & -0.12 & $-0.29^{*}$ \\
& WVDs & $1.17^{*}$ & -0.01 & -0.30 & $2.17^{*}$ & $1.50^{*}$ \\
\hline
\end{tabular}

\section{Contributions of different factors to the change in AEC}

Based on Eqs. (2) and (3), we further investigate the contribution of different factors to the projected change in AEC. For brevity, we only show the results for the period 2046-2065 in the following, because the case for the period 2080-2099 is similar.

Figure $9 \mathrm{a}$ and $\mathrm{b}$ exhibits relative contributions to the annual AEC change over the course of 2046-2065 from changes in precipitation and ventilation, respectively. Overall, the ventilation change plays a dominant role and contributes positively to the change in the AEC over most parts of China, particularly in western and northern China (Fig. 9b). In contrast, the relative contribution of the precipitation change is in general negative over western and northern China but positive over southern China (Fig. 9a).

According to Eq. (3), the effect of ventilation change can be decomposed into four terms, i.e. wind speed change, boundary layer depth change, non-linear term, and transient term. Among these contributors to annual ventilation change, the effects of boundary layer depth (Fig. 9d) and wind speed (Fig. 9c) are relatively large and the former is greater than the latter over most parts of eastern China. The transient term also exerts effects, for instance over some parts of western and southern China (Fig. 9f), while the effects of the nonlinear term are tiny across China (Fig. 9e).

Figure 10 further presents relative contributions of aforementioned factors to annual and seasonal AEC change over the four economic zones as projected by the ensemble and its members. As shown in Fig. 10a and b, changes in wind speed and boundary layer depth have the greatest contributions to the AEC change over the THB and NEC regions for the annual mean and all the seasons except summer. The contribution from the precipitation is in general relatively small. Besides, the effects of the transient term are larger than that of the precipitation, and the effects of the non-linear term can be negligible. These results indicate that changes in wind speed and boundary layer depth are the leading contributors respon- sible for the AEC change over the two regions. In contrast, over the YRD (Fig. 10c) and PRD (Fig. 10d) zones, change in precipitation also plays an important role. The contribution from the precipitation change is comparable to and even larger than that from changes in wind speed and boundary layer depth for all the seasons except winter.

\section{Conclusions}

In this study, we conducted downscaling simulations by use of the RegCM4 driven by three CMIP5 models' results under the historical simulation and the RCP4.5 scenario. On this basis, we evaluated the fidelity of the RegCM4 simulations on the AEC and WVDs, which are indictors of haze pollution potential, and then projected their change during the middle and the end of this century for China and the four main economic zones. The major findings are summarized below:

1. The evaluation indicates that the RegCM4 downscaling simulations in general show good performance in modelling the climatological distribution of the annual and seasonal AEC despite some discrepancies in certain regions. The spatial correlations between the simulation and the observation for the annual mean and four seasons are higher above 0.6 . The simulations also successfully capture the observed WVD pattern with relatively small WVDs over Tibet and relatively large WVDs over central and eastern China, Northeast China, south of northern China and Xinjiang, although WVDs are overestimated systematically.

2. The annual AEC and WVDs are respectively projected by the ensemble to decrease and increase in almost the entire region except central China, accompanied by larger amplitude by the end of the 21st century than by the middle of the 21 st century. The decreases in AEC are relatively large over Tibet, south-western China, north of northern China, Northeast China and Inner Mongolia. The increase in WVDs is particularly 

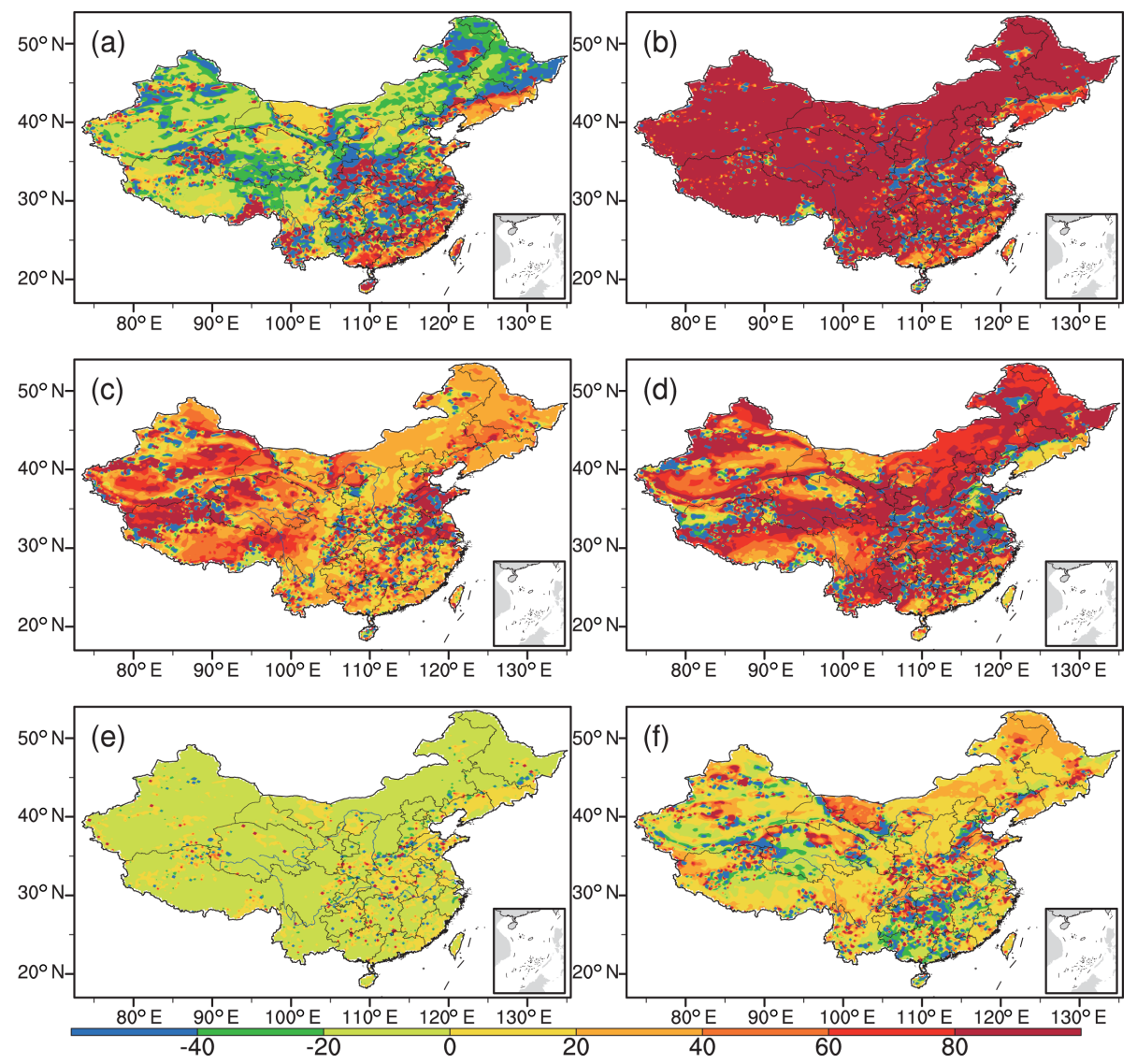

Figure 9. Relative contributions (unit: \%) of individual components to annual AEC change in the middle of the 21 st century based on the ensemble results. (a) Precipitation, (b) ventilation, (c) wind speed averaged within the boundary layer, (d) boundary layer depth, (e) non-linear term, (f) transient term.

pronounced in northern China. The individual members present consistent projections of changes as the ensemble. In contrast, the ensemble projects an increase in AEC and a decrease in WVDs over central China. However, the sign of the projected change is inconsistent among the ensemble samples.

3. The consistency analysis suggests that there would be a high probability of an increase in air pollution risk over the BTH and YRD regions in winter and over the PRD zone in spring and summer in a warmer climate. Over NEC, climate change might reduce the AEC or increase the WVDs throughout the whole year, which is favourable for the occurrence of haze pollution and also indicative of an aggravation of haze pollution risk. Furthermore, the contribution analysis indicates that changes in boundary layer depth and wind speed play leading roles in the AEC change over the BTH and NEC regions. In addition to the aforementioned two factors, the precipitation change is also an important factor influencing the AEC change over the YRD and PRD zones.
In this study, we mainly showed the downscaled results driven by three global models. Note that the planetary boundary layer depth is not a standard CMIP5 output variable, and the coarse vertical resolution of the global models prevents us from estimating the planetary boundary layer depth. These make it hard to estimate whether the consistencies and inconsistencies of the projection are caused by the global models or are to some extent affected by the dynamical downscaling of the regional model. Besides, it should be emphasized again that our study focused on the atmospheric carrying capacity, which is associated with the wet deposition and the ventilation. It is just one of the contributors to the haze change. Other factors such as emission, wind direction, and relative humidity are also vital for the incident of haze. The interaction between aerosol and climate is another important issue (Qian et al., 2015; Li et al., 2016). To get a full picture of future change of the haze, their effects need to be studied by models with chemistry/aerosol module coupled in future work. 

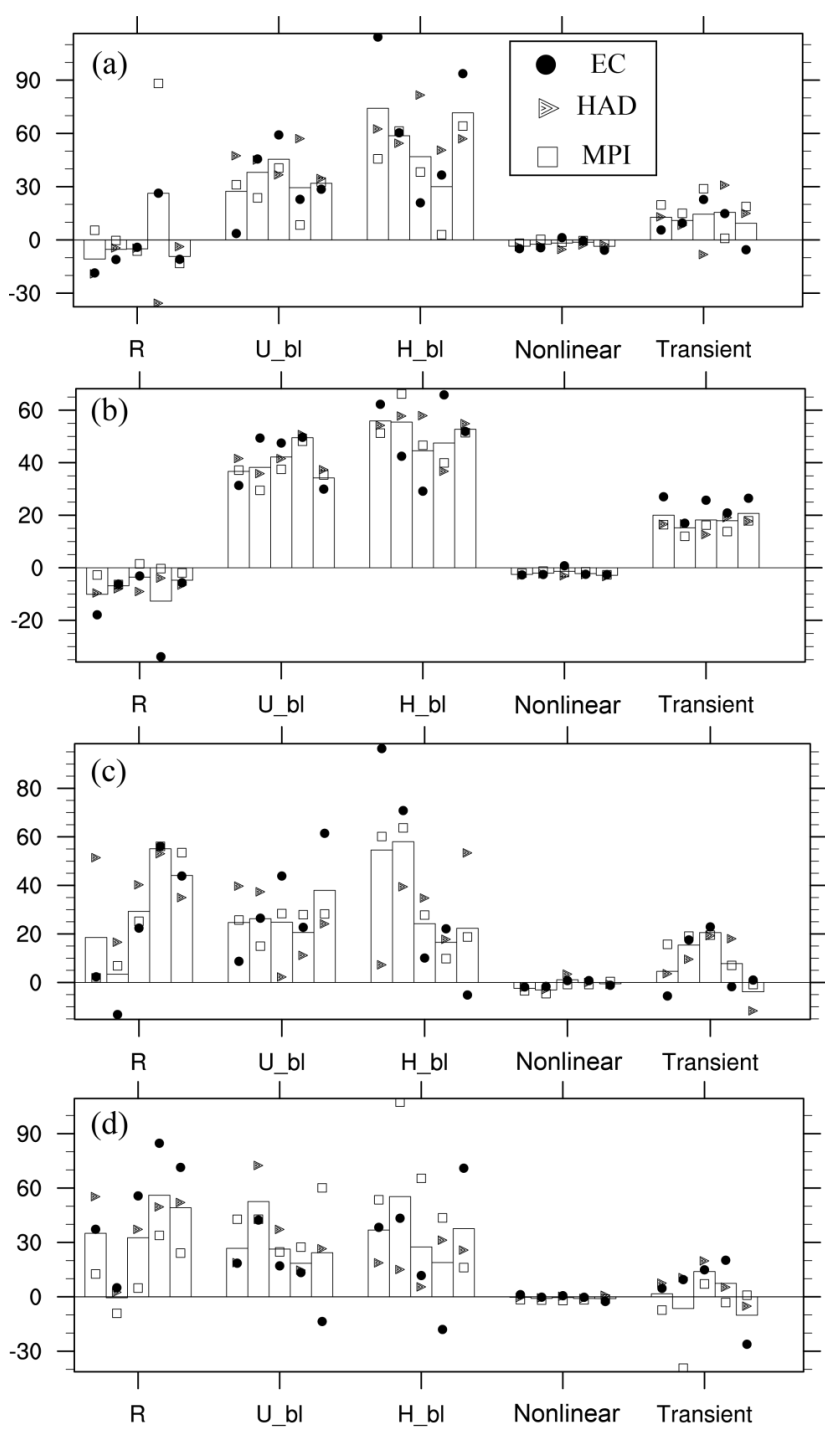

Figure 10. Relative contributions (unit: \%) of individual components to annual AEC change in the middle of the 21 st century averaged over the four main economic zones of China: (a) BTH, (b) NEC, (c) YRD, (d) PRD. The bars represent the ensemble projection and the marks represent the individual projection of the three members. Bars from left to right in each group are in turn for annual, DJF, MAM, JJA, and SON.

Data availability. ECMWF ERA-Interim data used in this study is available from the ECMWF data server: http://apps.ecmwf.int/ datasets/data/interim-full-daily/ (ECMWF, 2017). Model outputs are available upon request from the corresponding author.

Competing interests. The authors declare that they have no conflict of interest.
Acknowledgements. This research was jointly supported by the National Key Research and Development Program of China (2016YFA0600701), the National Natural Science Foundation of China (41675069, 41405101), and the Climate Change Specific Fund of China (CCSF201626, CCSF201731).

Edited by: Yun Qian

Reviewed by: three anonymous referees

\section{References}

Cai, W., Li, K., Liao, H., Wang, H., and Wu, L.: Weather conditions conducive to Beijing severe haze more frequent under climate change, Nature Climate Change, 7, 257-262, 2017.

Chen, H. P. and Wang, H. J.: Haze days in North China and the associated atmospheric circulations based on daily visibility data from 1960 to 2012, J. Geophys. Res.-Atmos., 120, 5895-5909, https://doi.org/10.1002/2015JD023225, 2015.

Ding, Y. H. and Liu, Y. J.: Analysis of long-term variations of fog and haze in China in recent 50 years and their relations with atmospheric humidity, Sci. China Earth Sci., 57, 36-46, 2014.

ECMWF: ERA-Interim data, available at: http://apps.ecmwf.int/ datasets/data/interim-full-daily/, last access: May 2017.

Emanuel, K. A.: A scheme for representing cumulus convection in large-scale models, J. Atmos. Sci., 48, 2313-2329, 1991.

Gao, G.: The climatic characteristics and change of haze days over China during 1961-2005, Acta Geogr. Sin., 63, 762-768, 2008.

Gao, X., Shi, Y., Zhang, D., Wu, J., Giorgi, F., Ji, Z., and Wang, Y. Uncertainties in monsoon precipitation projections over China: results from two high-resolution RCM simulations, Clim. Res., 52, 213-226, 2012.

Gao, X., Shi, Y., and Giorgi, F.: Comparison of convective parameterizations in RegCM4 experiments over China with CLM as the land surface model, Atmos. Ocean. Sci. Lett., 9, 246-254, 2016.

Gao, X., Shi, Y., Han, Z., Wang, M., Wu, J., Zhang, D., $\mathrm{Xu}$, Y., and Giorgi, F.: Performance of RegCM4 over major river basins in China, Adv. Atmos. Sci., 34, 441-455, https://doi.org/10.1007/s00376-016-6179-7, 2017.

Giorgi, F., Jones, C., and Asrar, G.: Addressing climate information needs at the regional level: the CORDEX framework, WMO Bull., 58, 175-183, 2009.

Giorgi, F., Coppola, E., Solmon, F., Mariotti, L., Sylla, M., Bi, X., Elguindi, N., Diro, G., Nair, V., Giuliani, G., Turuncoglu, U., Cozzini, S., Güttler, I., O’Brien, T., Tawfik, A., Shalaby, A., Zakey, A., Steiner, A., Stordal, F., Sloan, L., and Brankovic, C.: RegCM4: model description and preliminary tests over multiple CORDEX domains, Clim. Res., 52, 7-29, 2012.

Goyal, S. and Rao, C. C.: Air assimilative capacity-based environment friendly siting of new industries - A case study of Kochi region, India, J. Environ. Manage., 84, 473-483, 2007.

Guo, H., Xu, M., and Hu, Q.: Changes in near-surface wind speed in China: 1969-2005, Int. J. Climatol., 31, 349-358, 2011.

Han, Z., Gao, X., Shi, Y., Wu, J., Wang, M., and Giorgi, F. Development of Chinese high resolution land cover for the RegCM4/CLM and its impact on regional climate simulation (in Chinese), Journal of Glaciology and Geocryology, 37, 857-866, 2015. 
Hanson, K. R. and McKee, T. B.: Potential for regional air pollution episodes in Colorado. Atmospheric Science Paper No. 375, Colorado State University, Department of Atmospheric Science, Fon Collins, CO, 1983.

He, H., Wang, X. M., Wang, Y. S., Wang, Z. F., Liu, J. G., and Chen, Y. F.: Formation mechanism and control strategies of haze in China (in Chinese), Bull. Chinese Acad. Sci., 28, 344-352, 2013.

Holtslag, A. A. M., De Bruijn, E. I. F., and Pan, H. L.: A high resolution air mass transformation model for short-range weather forecasting, Mon. Weather Rev., 118, 1561-1575, 1990.

IPCC: Climate Change 2013: The Physical Science Basis. Contribution of Working Group I to the Fifth Assessment Report of the Intergovernmental Panel on Climate Change, Cambridge University Press, Cambridge, United Kingdom and New York, NY, USA, 1535 pp., 2013.

Jacob, D. J. and Winner, D. A.: Effect of climate change on air quality, Atmos. Environ., 43, 51-63, 2009.

Jiang, Y., Luo, Y., and Zhao, Z. C.: Maximum wind speed changes over China, Acta Meteorol. Sin., 27, 63-74, 2013.

Kang, Z., Gui, H., Hua, C., Zhang, B., Zhang, H., Lv, M., and Wang, J.: National Environmental Meteorological Services in China, Adv. Meteorol., 2016, 1985207, https://doi.org/10.1155/2016/1985207, 2016.

Kassomenos, P., Kotroni, V., and Kallos, G.: Analysis of climatological and air quality observations from greater Athens area, Atmos. Environ., 29, 3671-3688, 1995.

Kendall, M. G.: Rank Correlation Methods. Griffin, London, 1975.

Kiehl, J., Hack, J., Bonan, G., Boville, B., Williamson, D., and Rasch, P.: The National Center for Atmospheric Research Community Climate Model: CCM3, J. Clim., 11, 1131-1149, 1998.

Krishnan, P. and Kunhikrishnan, P.: Temporal variations of ventilation coefficient at a tropical Indian station using UHF wind profiler, Curr. Sci, 86, 447-451, 2004.

Lee, J. and Hong, S.: Potential for added value to downscaled climate extremes over Korea by increased resolution of a regional climate model, Theor. Appl. Climatol., 117, 667-677, 2014.

Leung, L. R. and Gustafson, W. I.: Potential regional climate change and implications to US air quality, Geophys. Res. Lett., 32, L16711, https://doi.org/10.1029/2005GL022911, 2005.

Li, Q., Zhang, R. H., and Wang, Y.: Interannual variation of the winter-time fog-haze days across central and eastern China and its relation with East Asian winter monsoon, Int. J. Climatol., 36, 346-354, https://doi.org/10.1002/joc.4350, 2015.

Li, Z., Lau, W. K. M., Ramanathan, V., Wu, G., Ding, Y., Manoj, M. G., Liu, J., Qian, Y., Li, J., Zhou, T., Fan, J., Rosenfeld, D., Ming, Y., Wang, Y., Huang, J., Wang, B., Xu, X., Lee, S. S., Cribb, M., Zhang, F., Yang, X., Zhao, C., Takemura, T., Wang, K., Xia, X., Yin, Y., Zhang, H., Guo, J., Zhai, P. M., Sugimoto, N., Babu, S. S., and Brasseur, G. P.: Aerosol and monsoon climate interactions over Asia, Rev. Geophys., 54, 866-929, https://doi.org/10.1002/2015RG000500, 2016.

Liu, J. and Diamond, J.: China's environment in a globalizing world, Nature, 435, 1179-1186, 2005.

Manju, N., Balakrishnan, R., and Mani, N.: Assimilative capacity and pollutant dispersion studies for the industrial zone of Manali, Atmos. Environ., 36, 3461-3471, 2002.

Mann, H. B.: Nonparametric tests against trend, Econometrica, 13, 245-259, 1945.
Oleson, K., Niu, G. Y., Yang, Z. L., Lawrence, D., Thornton, P., Lawrence, P., Stöckli, R., Dickinson, R., Bonan, G., and Levis, S.: Improvements to the Community Land Model and their impact on the hydrological cycle, J. Geophys. Res., 113, G01021, https://doi.org/10.1029/2007JG000563, 2008.

Pal, J. S., Small, E. E., and Eltahir, E. A. B.: Simulation of regionalscale water and energy budgets: Representation of subgrid cloud and precipitation processes within RegCM, J. Geophys. Res., 105, 29579-29594, 2000.

Park, T. W., Deng, Y., and Cai, M.: Feedback attribution of the El Niño-Southern Oscillation-related atmospheric and surface temperature anomalies, J. Geophys. Res.-Atmos., 117, D23101, https://doi.org/10.1029/2012jd018468, 2012.

Pimonsree, S.: PM10 dispersion during air pollution episode in Saraburi, Thailand, Asia-Pacific Journal of Science and Technology, 13, 1185-1190, 2008.

Qian, Y., Yasunari, T. J., Doherty, S. J., Flanner, M. G., Lau, W. K., Ming, J., Wang, H., Wang, M., Warren, S. G., and Zhang, R.: Light-absorbing particles in snow and ice: Measurement and modeling of climatic and hydrological impact, Adv. Atmos. Sci., 32, 64-91, 2015.

Sen, P. K.: Estimates of the regression coefficient based on Kendall's tau, J. Am. Stat. Assoc., 63, 1379-1389, 1968.

Song, L. C., Gao, R., Li, Y., and Wang, G. F.: Analysis of China's haze days in the winter half-year and the climatic background during 1961-2012, Adv. Clim. Change Res., 5, 1-6, 2014.

Taylor, K. E., Stouffer, B. J., and Meehl, G. A.: An overview of CMIP5 and the experiment design, Bull. Am. Meteorol. Soc., 93, 485-498, 2012.

Theil, H.: A rank-invariant method of linear and polynomial regression analysis, Proceedings of the Royal Netherlands Academy of Sciences, 53, I: 386-392, II: 521-525, III: 1397-1412, 1950.

Tian, D., Guo, Y., and Dong, W. J.: Future changes and uncertainties in temperature and precipitation over China based on CMIP5 models, Adv. Atmos. Sci., 32, 487-496, https://doi.org/10.1007/s00376-014-4102-7, 2015.

Trail, M., Tsimpidi, A. P., Liu, P., Tsigaridis, K., Hu, Y., Nenes, A., and Russell, A. G.: Downscaling a global climate model to simulate climate change over the US and the implication on regional and urban air quality, Geosci. Model Dev., 6, 1429-1445, https://doi.org/10.5194/gmd-6-1429-2013, 2013.

Uppala, S., Dee, D., Kobayashi, S., Berrisford, P., and Simmons, A.: Towards a climate data assimilation system: Status update of ERA-Interim, ECMWF newsletter, 115, 12-18, 2008.

Wang, H.-J. and Chen, H.-P.: Understanding the recent trend of haze pollution in eastern China: roles of climate change, Atmos. Chem. Phys., 16, 4205-4211, https://doi.org/10.5194/acp16-4205-2016, 2016.

Wang, H. J., He, S. P., and Liu, J. P.: Present and future relationship between the East Asian winter monsoon and ENSO: Results of CMIP5, J. Geophys. Res.-Ocean, 118, 1-16, https://doi.org/10.1002/jgrc.20332, 2013.

Wang, H. J., Chen, H. P., and Liu, J. P.: Arctic sea ice decline intensified haze pollution in eastern China, Atmos. Ocean. Sci. Lett., 8, 1-9, 2015.

Wang, X. P. and Mauzerall, D. L.: Evaluating impacts of air pollution in China on public health: implications for future air pollution and energy policies, Atmos. Environ., 40, 1706-1721, 2006. 
Wang, Y. S., Yao, L., Liu, Z. R., Ji, D. S.,Wang, L. L., and Zhang, J. K.: Formation of haze pollution in Beijing-Tianjin-Hebei region and their control strategies, Bull. Chinese Acad. Sci., 28, 353363, 2013.

Wang, Z. F., Li, J., Wang, Z., Yang, W. Y., Tang, X., Ge, B. Z., Yan, P. Z., Zhu, L. L., Chen, X. S., Chen, H. S., Wang, W., Li, J. J., Liu, B., Wang, X. Y., Wang, W., Zhao, Y. L., Lu, N., and Su, D. W.: Modeling study of regional severe hazes over Mid-Eastern China in January 2013 and its implications on pollution prevention and control, Sci. China: Earth Sci., 57, 3-13, https://doi.org/10.1007/s11430-013-4793-0, 2014.

Wu, D., Tie, X., Li, C. C., Ying, Z. M., Lau, A. K., Huang, J., Deng, X. J., and Bi, X. Y.: An extremely low visibility event over the Guangzhou region: A case study, Atmos. Environ., 39, 65686577, 2005.

Wu, D., Liao, G. L., Deng, X. J., Bi, X. Y., Tan, H. B., Li, F., Jiang, C. L., Xia, D., and Fan, S. J.: Transport condition of surface layer under haze weather over the Pearl River Delta, J. Appl. Meteorol. Sci., 19, 1-9, 2008.

Wu, J., Gao, X., Xu, Y., and Pan, J.: Regional climate change and uncertainty analysis based on four regional climate model simulations over China, Atmos. Ocean. Sci. Lett., 8, 147-152, $2015 \mathrm{a}$.

$\mathrm{Wu}$, J., Zhou, B. T., and Xu, Y.: Response of precipitation and its extremes over China to warming: CMIP5 simulation and projection, Chinese J. Geophys., 58, 3048-3060, https://doi.org/10.6038/cjg20150903, 2015b.
$\mathrm{Xu}, \mathrm{D}$. and Zhu, R.: A study on the distribution of ventilation and rainout capacity in mainland China (in Chinese), China Environ. Sci., 9, 367-374, 1989.

$\mathrm{Xu}$, P., Chen, Y. F., and Ye, X. J.: Haze, air pollution, and health in China, Lancet, 382, 2067, https://doi.org/10.1016/S01406736(13)62693-8, 2013.

$\mathrm{Xu}, \mathrm{Y}$. and $\mathrm{Xu}, \mathrm{C} . \mathrm{H}$., Preliminary assessment of simulations of climate changes over China by CMIP5 multi-models, Atmos. Ocean. Sci. Lett., 5, 489-494, 2012.

Yang, Y., Liao, H., and Lou, S.: Increase in winter haze over eastern China in recent decades: Roles of variations in meteorological parameters and anthropogenic emissions, J. Geophys. Res.-Atmos., 121, 13050-13065, https://doi.org/10.1002/2016JD025136, 2016.

Yin, Z. C., Wang, H. J., and Guo, W. L.: Climatic change features of fog and haze in winter over North China and Huang-Huai Area, Sci. China Earth Sci., 58, 1370-1376, 2015.

Zhang, R. H., Li, Q., and Zhang, R. N.: Meteorological conditions for the persistent severe fog and haze event over eastern China in January 2013, Sci. China: Earth Sci., 57, 26-35, 2014.

Zou, Y., Wang, Y., Zhang, Y., and Koo, J.-H.: Arctic sea ice, Eurasia snow, and extreme winter haze in China, Science Advances, 3, e1602751, https://doi.org/10.1126/sciadv.1602751, 2017. 